


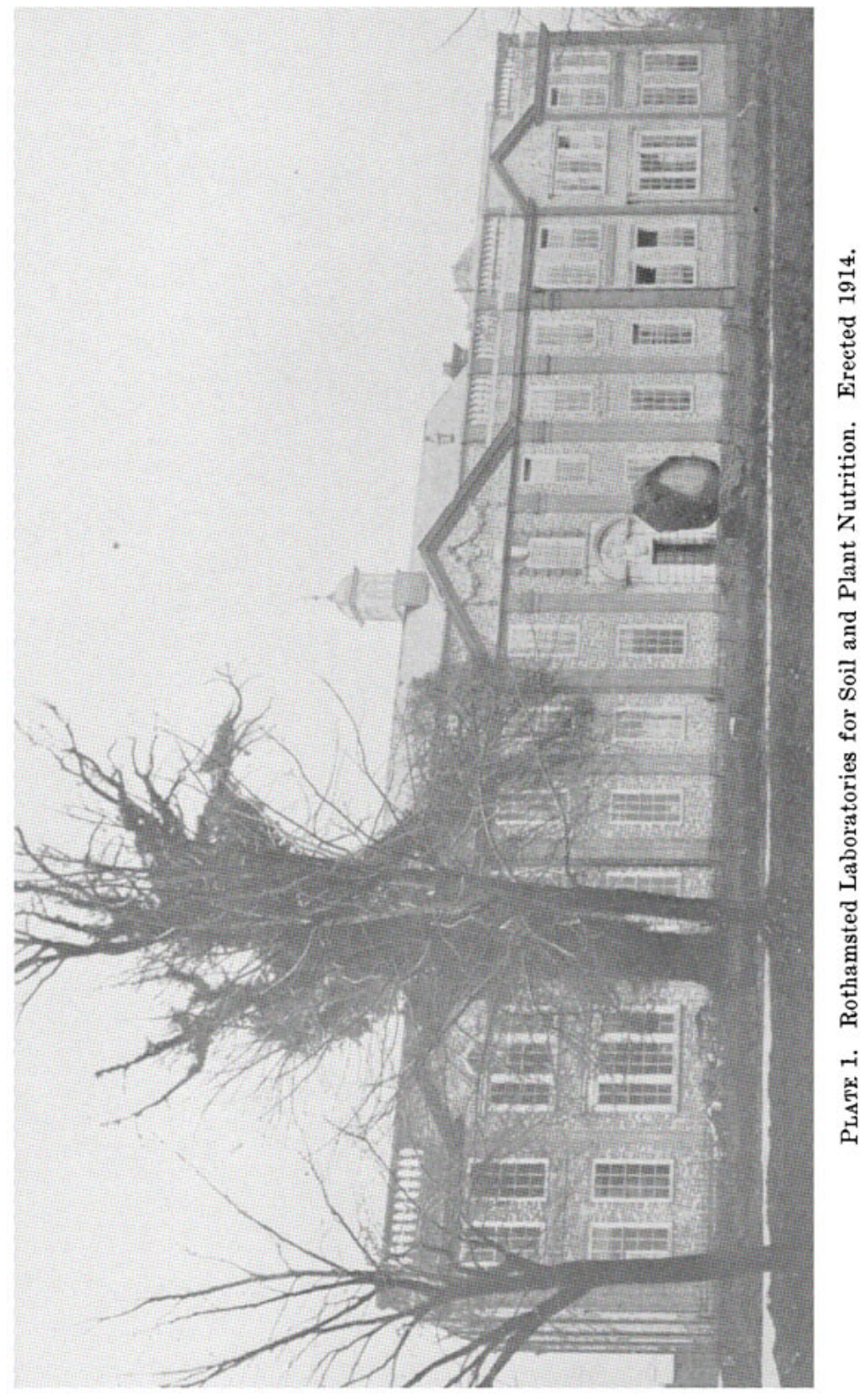




\section{PLANT NUTRITION AND CROP PRODUCTION}

BY

E. J. RUSSELL

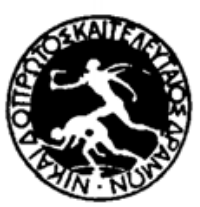

UNIVERSITY OF CALIFORNIA PRESS

BERKELEY, CALIFORNIA

1926 
THE HITCHCOCK LeCTURES FOR 1924

Copyright, 1926

BY THE

University of California Press

Printed in the United Stateg of AMerica 


\section{PLANT NUTRITION AND CROP PRODUCTION}


The University of Californta Press

Berkeley, CaJafFornia

U. s. A.

The Cambridge University Press

London, England 